edited and published, exposing criteria and referral method for PCP's offices.

Results: During the first 6 months 33 patients were correctly referred. $78.8 \%$ were women and the average age was 49 years old. $48.8 \%$ (16 patients) were diagnosed with some inflammatory arthropathy: $31.5 \%$ were RA (5 cases); other diagnoses were arthropathy due to microcrystals deposit (2), overlap SLE/RA (1), MCTD(1), psoriatic arthritis (1), spondyloarthritis associated with IBD (1) or inflammatory arthralgia associated with retroperitoneal fibrosis (1). $12 \%$ (4 patients) were diagnosed with hands incipient osteoarthritis and $33.8 \%$ (12 patients) with arthralgias without data on inflammatory pathology. One patient missed her follow-up. The median time from symptom onset to Rheumatology assessment was 90 days in all patients; in the inflammatory pathologies subgroup, $68.8 \%$ was assessed in $<12$ weeks, with a median of 60 days and a mean of 96 days, starting treatment in this subgroup in the first assessment by Rheumatology.

Conclusion: In our experience, the establishment of a specific protocol in collaboration with Primary Care for the preferential referral of patients with suspected recent onset arthritis, obtained diagnoses not only for patients with rheumatoid arthritis, but also for other systemic autoimmune diseases in early stages, as well as early treatment initiation $(<12$ weeks) in most of these patients. In addition, it turned out to be an effective and comfortable referral route for PCP with suspected connective and/or inflammatory arthritis.

Disclosure of Interests: Consuelo Ramos Giráldez Speakers bureau: Sanofi, María Espinosa: None declared, Carolina Merino Argumánez: None declared, Patricia Fernández Crespo: None declared, Olga Rusinovich: None declared, Fernando León Vázquez: None declared, José Luis Andreu Sánchez: None declared, Carmen Barbadillo Mateos: None declared

DOI: 10.1136/annrheumdis-2019-eular.6144

\section{AB1228 ACCESS TO RHEUMATOLOGIC TREATMENTS AND AUTOIMMUNE CONDITIONS IN LATIN AMERICA}

Genessis Maldonado ${ }^{1}$, Daniella Cobeña ${ }^{1}$, Enrique Soriano ${ }^{2}$, Letty Moreno ${ }^{3}$, Carlos Rios ${ }^{1,3} .{ }^{1}$ Espiritu Santo University, Rheumatology, Guayaquil, Ecuador, ${ }^{2}$ Hospital Italiano de Buenos Aires, Buenos Aires, Argentina; ${ }^{3}$ Centro de Reumatología y Rehabilitación, Guayaquil, Ecuador

\section{Background:}

Objectives: To know the availability of treatment for rheumatologic and autoimmune conditions in Latin America, according to rheumatologists in the region.

Methods: A digital survey was created using Google Forms, it was approved and endorsed by the scientific committee of PANLAR, and later sent to the different Rheumatology associations of the region. The data was analyzed in the statistical program SPSS v.23.

Results: 456 surveys were filled by rheumatologists from 23 countries. The majority were females (54\%). The mean age was $47.18 \pm 11.79$ [25-78] years. $91 \%$ reported access to DMARDs, methotrexate 95\%, azathioprine $94 \%$, cyclophosphamide $92 \%$, hydroxychloroquine $92 \%$, leflunomide $90 \%$, mycophenolate mofetil $90 \%$, sulfazalasin $88 \%$, cyclosporine $80 \%$, tacrolimus $64 \%$, chloroquine $60 \%$. $85 \%$ have access to biological therapy: adalimumab $(78 \%)$, etarnercept $(83 \%)$, rituximab $(81 \%)$, infliximab $(74 \%)$, tocilizumab $(73 \%)$, abatacept $(67 \%)$, golimumab $(63 \%)$, certolizumab $(59 \%)$, secukinumab (55\%), ustekinumab (44\%), certolizumab (59\%), belimumab (47\%), canakinumab (22\%), sarilumab (15\%), ixekizumab $(12 \%)$, anakinra $(10 \%)$ and rilonacept $(3 \%)$. 58\% have access to biosimilar drugs: rituximab (27\%), infliximab $(24 \%)$, etanercept $(18 \%)$ and adalimumab (4\%). $61 \%$ have access to small molecules such as: tofacitinib $62 \%$, baricitinib $18 \%$ and ruxolutinib $1 \%$. Regarding the survey by each country 95\% reported access to DMARDs: between $80-100 \%$ (Argentina, Bolivia, Brazil, Chile, Colombia, Costa Rica, Cuba, Ecuador, El Salvador, Guatemala, Honduras, Mexico, Nicaragua, Panama, Paraguay, Peru, Puerto Rico, Dominican Republic). $70 \%$ of the countries reported access to biological therapy between $80-100 \%$ (Argentina, Bolivia, Brazil, Chile, Colombia, Costa Rica, Ecuador, El Salvador, Guatemala, Honduras, Panama, Paraguay, Puerto Rico, Uruguay.) $15 \%$ did not have access to biosimilar therapy (Cuba, Honduras and Uruguay). $30 \%$ have access to therapy with small molecules between $80-100 \%$ (Argentina, Guatemala, Honduras, Panama, Paraguay and Dominican Republic), 25\% did not have access to small molecules (Cuba, Uruguay and Venezuela).
Conclusion: It is evident that most Latin American countries have access to drugs focused on rheumatic diseases, however, there are substantial differences in countries that do not have access to all therapies. In addition, newer treatment as small molecules are less accessible to the region.

Disclosure of Interests: None declared

DOI: 10.1136/annrheumdis-2019-eular.7861

\section{AB1229 RHEUMATIC DISEASES REMISSION DURING PREGNANCY: MYTH OR REALITY? FACT OR HOPE?}

Euthalia Roussou ${ }^{1,2}$, Josie O'heney ${ }^{3}$, Victoria Sampson ${ }^{3}$, Asma Aziz $^{3} .{ }^{1}$ London, Rheumatology, Romford London, United Kingdom; ${ }^{2}$ Barking Havering and Redbridge University Hospitals NHS Trust, Rheumatology, Romford London, United Kingdom; ${ }^{3}$ Barking Havering and Redbridge University Hospitals NHS Trust, Obstetrics and Gynaecology, Romford, United Kingdom

Background: A Rheumatology Obstetric Combined Clinic (ROCC) has been running in our trust since 2013 for patients with any musculoskeletal (Msk) rheumatological disease. Observing pregnant ladies in this clinic it became noticeable that patients with msk diseases do not always go into remission during pregnancy.

Objectives: To register their perception of disease activity during pregnancy and from their memory of that disease activity before pregnancy A secondary aim was to assess whether the remission (or flare) during pregnancy was disease specific or trimester specific.

Methods: Patients with Msk disorders attending ROCC were given 2 different $10 \mathrm{~cm}$ visual analogue scales (VAS) asking them to grade the current (at the time of the assessment in ROCC) disease activity and their perceived disease activity prior to pregnancy. The recorded diseases were: (1) Lupus and other Connective Tissue Diseases $=18[(33.3 \%)$ of whom 13 were having Lupus and 5 Sjogren's syndrome, (2)SPAs =16 $[(28.6 \%)$ of whom 4 had Ankylosing Spondylitis (AS) and 12 Psoriatic arthritis (PsA)], (3) Rheumatoid Arthritis (RA) $=9$ (16.7), Antiphospholipid Syndrome $($ APS $)=7(13 \%)$ and other $=4(7.4 \%)$. In the "other" group there was 1 patients with sarcoidosis, 1 with Adult Onset Still's disease, 1 JIA which progressed to CREST, 1 knee pain. The last group was excluded from the analysis. SPSS was used for statistical analysis and chi square to assess the difference between the 2 groups

Results: We analyzed data from 50 patients who attended the ROCC. A the time of presentation mean age $( \pm s d)$ was 33.4 years $( \pm 4.29)$ range $22-43 y$ while age of disease presentation was $25.5( \pm 8.06)$. The weeks (w) of pregnancy during the time of assessment were (mean) $22.2( \pm 8.6)$ range 8-37 w. ESR (mean in $\mathrm{mmHg}$ ) was 27 ( \pm 21.7 ), CRP 13.6 ( \pm 14.18 ). Disease activity at presentation on a VAS was 4.24 ( \pm 2.8$)$ while reported disease activity prior to pregnancy was exactly the same of 4.24 ( \pm 3.07$)$.

Looking at groups of diseases RA and SpA patients showed reduction in the reported disease activity during pregnancy while CTDs and APS showed an increase, both of which however was not statistically significant (ss (table1)

\begin{tabular}{lccc}
\hline $\begin{array}{l}\text { Diseases (nr of } \\
\text { patients) }\end{array}$ & $\begin{array}{c}\text { Disease activity during } \\
\text { pregnancy } \\
\text { [mean }( \pm \text { sd)] }\end{array}$ & $\begin{array}{c}\text { Disease activity before } \\
\text { pregnancy } \\
\text { [mean }(+ \text { sd)] }\end{array}$ & $\begin{array}{c}\text { Statistical } \\
\text { significance }\end{array}$ \\
\hline CTDs (18) & $4.5(2.6)$ & $3.93(2.4$ & 0.6 \\
SpAs (16) & $4.6(2.8)$ & $5.8(3.9)$ & 0.8 \\
RA (9) & $4.13(2.5)$ & $4.75(2.5)$ & 0.9 \\
APS $(7)$ & $2.2(3.1)$ & $1(1.7)$ & 0.4 \\
\hline
\end{tabular}

Looking at DA according to trimester, it was in the 1st trimester (up to week 13) that patients were reported remision. (table 2 and figure 1).

\begin{tabular}{|c|c|c|c|c|c|}
\hline $\begin{array}{l}\text { Trimester } \\
\text { ( } \mathrm{n}=\text { number of } \\
\text { patients) }\end{array}$ & ESR & CRP & $\begin{array}{l}\text { Disease activity } \\
\quad \text { (current) }\end{array}$ & $\begin{array}{l}\text { Disease activity } \\
\quad \text { (before) }\end{array}$ & $\begin{array}{l}\text { Ss (chi } \\
\text { square) }\end{array}$ \\
\hline $1^{\text {st }}(\mathrm{n}=14)$ & $6(6.9)$ & $20(30)$ & 1.64 ( 2.09) & $2.5(2.7)$ & 0.02 \\
\hline $2^{\text {nd }}(n=19)$ & $\begin{array}{c}30.2 \\
(35.5)\end{array}$ & $\begin{array}{c}16.8(\mathrm{SD} \\
+13.5)\end{array}$ & $4.4(3.6)$ & $4.2(3.5)$ & 0.2 \\
\hline $3^{r d}(n=18)$ & $\begin{array}{c}17.3 \\
(20.3)\end{array}$ & $\begin{array}{c}3.9(\mathrm{sd} \\
+5.5)\end{array}$ & 3.67 (2.56) & $3.4(3.14)$ & 0.4 \\
\hline
\end{tabular}

